\title{
Safety Culture App: An innovation in Safety Performance System at the Aviation Industry
}

\author{
AswathySreenivasan, Akshay MS, M Dhanya, Rajul Raj
}

\begin{abstract}
The purpose of this paper is to consider some of the innovation in improving employee's safety culture in the aviation industry. The aviation sectors are one of the fastestgrowing sectors in the world. Establishing a sound and robust safety Culture is essential for ensuring the safety and security of the employees. There are many technological innovations to control the tangible risk but are severely limited with options to tackle intangible risk. One of the common error is a human error which creates most of the hazardous problems. In this context to reduce human error, we propose a Safety Culture App that can address most of the problems to a reasonable extent.
\end{abstract}

Keywords: Safety Culture App, Aviation industry, risk

\section{INTRODUCTION}

India's Civil Aviation Industry has been found one of the fastest-growing industries in the country in the past 3 years. It is one of the high-risk prone areas and as in other safetycritical system, errors are inevitable. The root causes of accidents are identified to be human errors. To understand what causes an error, it is necessary to evolve beyond the limited scope of tracing the erroneous action of the individual. Each small error in the system will create countless undetected hazards. Thus many types of research were conducted to reduce the adverse effect of the error on the outcome of a system breach by producing meticulously developed tools, technologies, and procedures to provide the buffer in a system to incorporate error tolerance. Many studies where carried out to come out with a solution and one among them was to implement the concept of safety culture in an organization Safety culture is a term that nearly everyone uses but few can agree on its precise meaning or how it can be measured. The social as a first, it comprises the beliefs, attitudes, and values often unspoken of an organization's membership regarding the pursuit of safety and the second is more concrete and embraces the structures, practices, controls and policies that organisations possess and employees to achieve greater safety. A combination of workplace safety and large-scale disaster has encouraged a high-risk organisation to encourage the idea of safety culture to reduce the potential workplace incidents and safety with routine tasks.

Revised Manuscript Received on December 30, 2019.

* Correspondence Author

Aswathy Sreenivasan, Pursuing Department of MBA degree Amrita Vishwa Vidyapeetham, India.

Akshay M S, Pursuing Department of M.B.A. degree Amrita Vishwa Vidyapeetham, India,

Dr.Dhanya M, Assistant Professor (Senior Grade) Amrita University, Kochi, India.

Mr.Rajul Raj, Assistant System Analyst Tata Consultancy Services,

(C) The Authors. Published by Blue Eyes Intelligence Engineering and Sciences Publication (BEIESP). This is an open access article under the CC BY-NC-ND license (http://creativecommons.org/licenses/by-nc$\underline{\mathrm{nd} / 4.0 /)}$
Safety Culture plays an important role in determining an organisation's success and failure. So here in this study, we try to propose a new technology to improve safety culture in an organisation. The mode of an individual's interaction with each other has changed widely as mobile technologies and networks are increasingly expanding their capacity and sophistication. From a survey conducted in 2014, it was found that mobile devices can be used as an ideal platform for inspecting behaviour, self-monitoring, and getting personalised feedback and to bring motivational support [1]. In India, almost 233 million people are using smartphones. So it is easy to penetrate people's mind the application of safety using an app. The purpose of this paper is to make a review on challenges faced in aviation industry safety department and also how can it be reduced using implementing safety culture app.

\section{LITERATURE REVIEW}

Aviation Industry is one of the prominent growing sectors in India. The main issue India is lagging in terms of safety, historically aviation safety was built upon the reactive analysis of past accidents and then corrective actions were taken. But due to the huge reduction in incident occurrence data are very less so there came a necessity of using proactive analysis to reduce safety occurrence in aviation industries [2].In 2017, 1559 runway incursion of which 256 was vehicle/pedestrian deviation. From the study, it was found out most of the people involved in such cases have no business to enter airfield, but they enter deliberately or inadvertently [3].

We cannot generalise situations in 2 airports, benchmarking is necessary to a limit but it cannot be done throughout. Every airport has KPI on safety and security, the main focus in airports is the role of facility management [4]. It is very important to build a better airport with improved quality and safety systems. It is easy for any aviation safety issue to be drowned by management and it won't come out, keeping these issues in front and centre with the community leaders and common citizen to build a better facility[5]. Much theoretical research has been developed in the field of human factors relating to accident-prone, such as SHEL Model, Reason's Swiss Cheese Model and HFACS. Some of these models are applied in the aviation industries also [6]. There was a range of incidents occurred in aviation and marine due to the team-based interaction with the safety-critical programmable system between December 2001 and February 2003. Here also human error was found to be the primary cause of accidents [7]. The fundamentals and structures of the Safety Management System, need and development. 
SMS is to be taught in every aviation industries [8]. The SMS is an integrated approach and comprehensive towards safety based on the assessment of risk and the concept of management.

It mainly consists of 3 basic steps of prevention, control and containment of consequence derived from hazardous events [9]. An integrated model of incorporating risk is ATM technologies, aircraft, staff and crew, routes and weather [10]. This integrated safety performance system designed to be scalable up to European level and applicable to the Single European Sky concept [11].Considering the airport in terms of logistics, it is the link of the supply chain in air transport that jointly allows expanding the airport internal safety audit scope for sustainable development, security and continuity of the supply chain [12]

\section{ANALYSIS}

As per EASA norms, each airport should conduct a safety culture survey every 3 years. But most of the airports won't spend time in these surveys. Visited 2 private airports in India and made a study when this survey was conducted last, and it was found out this survey was not conducted past 7 years. Made a pilot study with executive employees in the airport and found out that only $70 \%$ of employees got initial safety training.

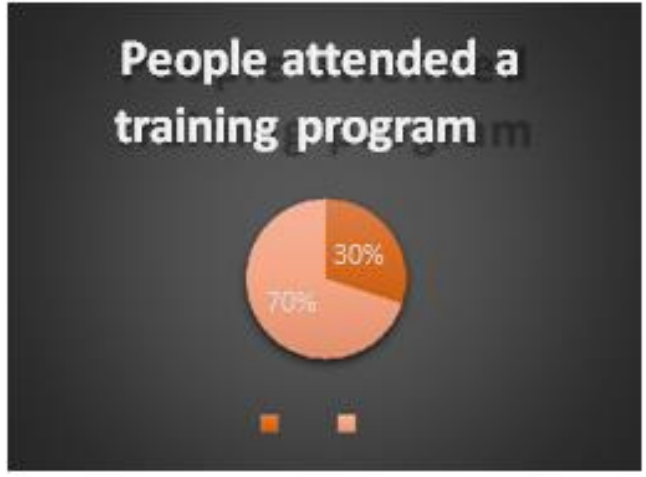

The safety culture survey was conducted based on 6characteristics: Commitment, Awareness, Adaptability, Justness, Information, and Behaviour
[13]. The output was calculated using the Safety Culture Maturity Model prescribed by Patrick Hudson.

From this analysis, we concluded that the main safety issue is human errors and to rectify this

safety awareness should be improved. For this after conducting a brainstorming session with people in aviation sector came up with an idea of safety culture app.

Before implementing an app a market study is done going to some private airports in India and surveyed to identify people's awareness about safety. The result is being shown below.

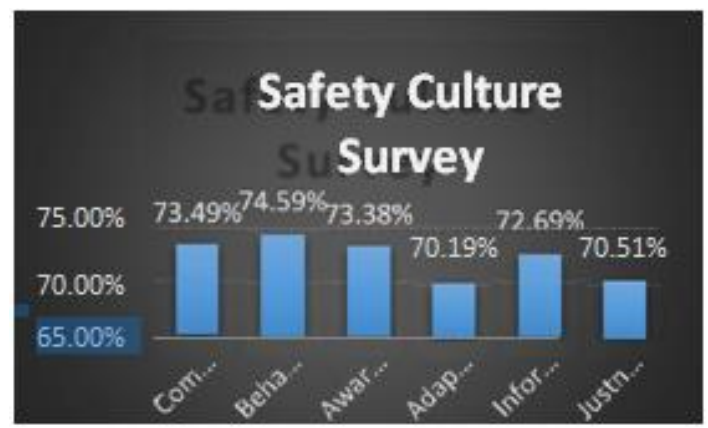

Made a literature study on safety issues occurring at 6 airports in China. It clearly stated that every year the safety incidents increase prominently [2].

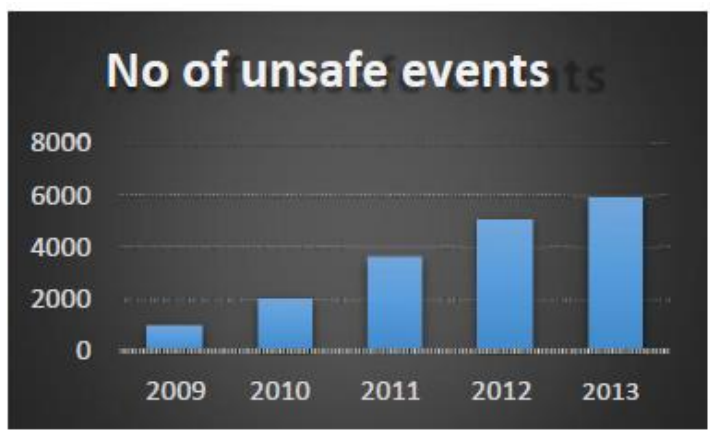

IV. PROPOSED MODEL

A detailed business canvas model has been developed using sequoia capital model, which shows the distribution channel, how revenue can be generated, what should be the cost structure etc.

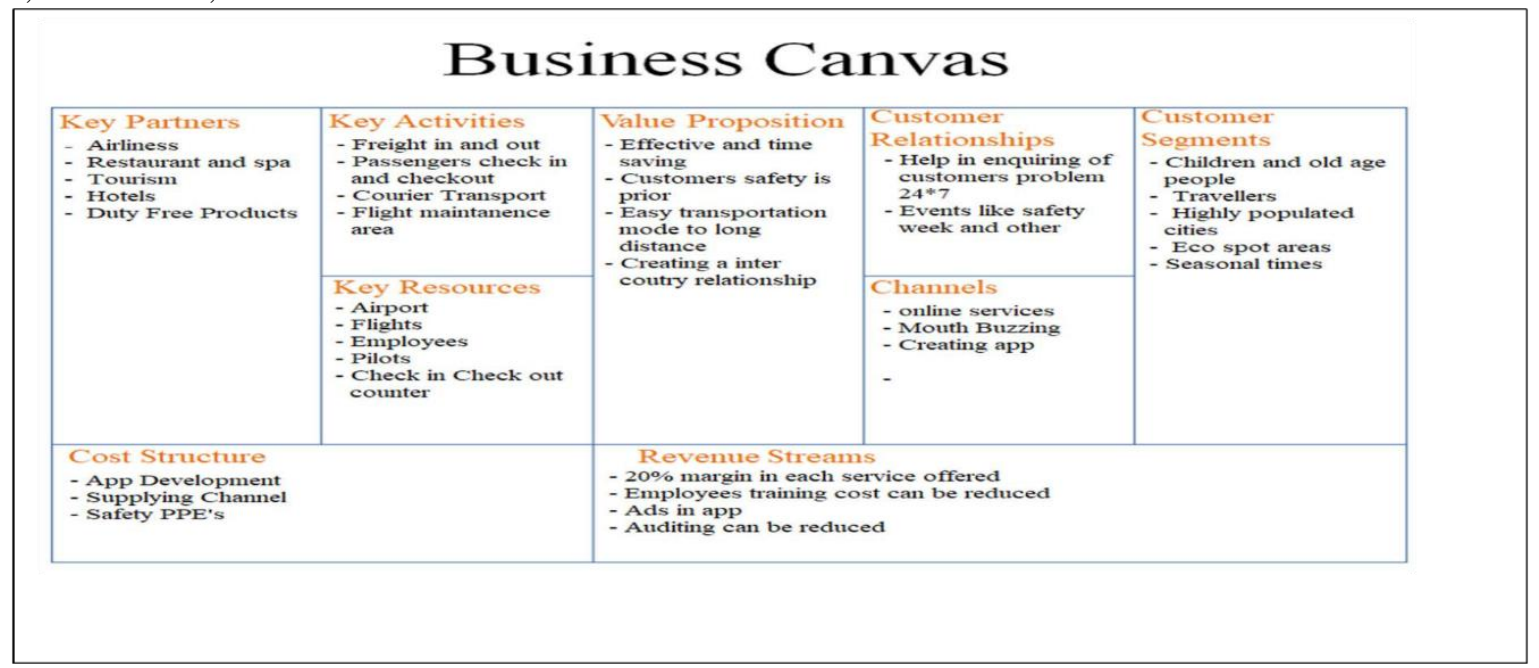

Figure 1: Business Model for safety culture app 


\section{Advantages of Safety Culture App}

Safety policies can be updated and notified in the app

Training sessions can be conducted online

Report safety issues and queries in it

Employee retention rate can be increased

No OSHA audit or fines

Lower accident rate

\section{CONCLUSION}

For any country to come forward in terms of quality and service in the aviation industry, safety is one of the predominant factors. Most of the airport is currently technologically sound, the main demerit is to rectify this, a Safety Culture App currently technologically good, the main demerit is human errors. To rectify this, a Safety Culture Appis human errors.To rectify this, a Safety Culture App is suggested which would bring a huge variation in employees awareness about safety. This is just an initial stage, this app can also be used in other industries also like hospitality, logistics, textile etc.

\section{REFERENCES}

1. K. G. Giota and G. Kleftaras, "Mental Health Apps: Innovations, Risks and Ethical Considerations," E-HealthTelecommunication Systems and Networks, p. 6, 2014.

2. Bala, S. K. Sharma, S. Kumar and R. Shrivastava, "Exploring Safety Aspects of Aviation Industry," Advances inAerospace Science and Applications.,vol.4, p. 8, 2014.

3. C. Castanga, "Creating a Culture of Safety is Everyone's Business," AIRFIELDSAFETY, p. 2, July 2017.

4. A. Enoma, s. Allen and a. Enoma, "Airport redesign for safety and security: case studies of three Scottish airports," International Journal of Strategic Property Management, p. 15, 2009.

5. J. Petrie, "A Change Now to Change Later," Airport Business, p. 2, September 2017.

6. S. Ruishan, W. Lei and Z. Ling, "Analysis of Human Factors Integration Aspects for Aviation Accidents and Incidents," Springer-Verlag Berlin Heidelberg, p. 2, 2007.

7. C. Johnson, "The team-based operation of safety-critical programmable systems in us commercial aviation and the UK maritime industries," Glasgow, 2009.

8. R. Muller and C. Drax, "Fundamentals and Structure of Safety Management Systems in Aviation," International Civil Aviation Organisation, Switzerland, 2009.

9. P. Cacciabue, M. Cassani, V. Licata, I. Odonne and A. Ottmaniello, "A practical approach to assess risk in aviation domains for safety management systems," Springer, p. 19, 2015.

10. J.-n. Zhao, L.-n. Shi and L. Zhang, "Application of improved unascertained mathematical model in security evaluation of civil airport," Int J Syst Assur EngManag, p. 12, 2017.

11. N. McDonald, S. Corrigan, P. Ulfvengren and D. Baranzini, "Proactive Safety Performance for Aviation Operations," Springer International Publishing Switzerland, p. 12, 2014.

12. M. Kozlowski, "Integrated Airport Safety Audit," Scientific Journal of Logistic, p. 12, 2017.

13. E. Craig, "Building a safety culture on ground," Safety in Aviation, p. 6, February 2005.

\section{AUTHORS PROFILE}

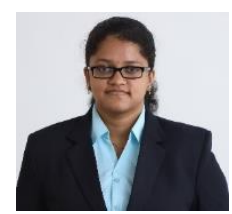

Aswathy Sreenivasan, is pursuing her MBA degree from Amrita Vishwa Vidyapeetham, India. She is specializing in Business Analytics and Finance. As part of her MBA, she interned at Geojit Financial Services Ltd., Kochi and completed her internship project titled "Differentiating Winners and Losers Using Fundamental Information". She also obtained her Bachelor of Commerce in Accounts and Finance from North Eastern Hill University, India, in 2018. She has completed her Diploma in Accounts and Finance from NIIT, India. She has also successfully completed the "Certified Alternative Investment Manager (AIM)" certification from Association of International Wealth Management of India (AIWMI). Her area of interest are financial modelling, data mining, data visualization and forecasting, and data driven marketing.

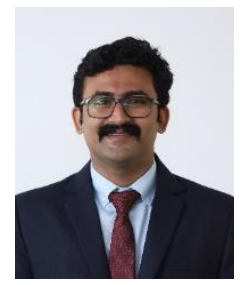

Akshay M S, is pursuing his M.B.A. degree from Amrita Vishwa Vidyapeetham, India, specializing in Business Analytics and Marketing.As part of his M.B.A., he interned at Amrita Institute of Medical Sciences, Kochi and completed his internship project in Health Care Analytics, titled "Early Detection of Thyroid Cancer using Logistic Regression". He also obtained his Bachelor of Technology degree in Mechanical Engineering from Cochin University of Science and Technology, India, in 2017. His UG project was titled "Increasing the efficiency of IC engine using Ferro Fluid as coolant”. He has been offered Business Analyst role at TATA Consultancy Services. His interests are data mining, data visualization and data driven marketing.

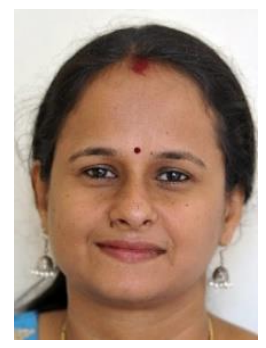

Dr.Dhanya $\mathbf{M}$, is an Assistant Professor (Senior Grade) in Amrita University, Kochi, India. She has graduated her Master of Science (M.Sc.) in Statistics and also holds a Master's degree in Business Administration (MBA). She obtained her UGC-NET in Management and M. Phil. in Statistics. She received her $\mathrm{PhD}$ degree in Statistics on the topic "Estimation of reliability measures of some heavy tailed life time distributions"from Mahatma Gandhi University, India. Her areas of interest include Statistical Inference, Stress Strength Reliability, Bayesian Estimation, Operations Research and Business Analytics. She has published research papers in reputed national and international journals. She is a member of the Kerala Statistical Association.

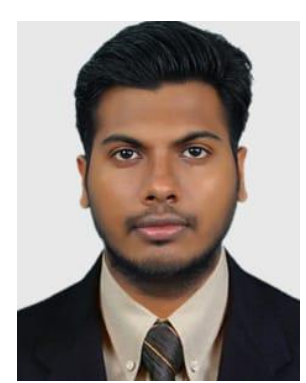

Mr.Rajul Raj, is an Assistant System Analyst in Tata Consultancy Services, one among the highly reputed multinational companies in our country. He is a former MBA student at Amrita School of Business in finance and Operations. As a part of his post graduation he did a project titled 'Monitoring and safety culture survey' in Mumbai International airport ltd. He has done his B Tech in Mechanical Engineering from AWH engineering College. His UG project was 'Remodification of economiser' in FACT. His areas of interest include financial modelling, data mining, data visualization and forecasting. 